\title{
Realizing the Value Proposition: A Longitudinal Assessment of Hospitals' Total Factor Productivity
}

\author{
Timothy R. Huerta, MPA, PhD ${ }^{1 *}$; Eric W. Ford, MPH, PhD²; William F. Ford, \\ $\mathbf{P h D}^{3}$, Mark A. Thompson, $\mathbf{P h D}^{\mathbf{1}}$ \\ ${ }^{1}$ Rawls College of Business, Texas Tech University, Lubbock, TX, USA \\ ${ }^{2}$ Bryan School of Business, The University of North Carolina Greensboro, \\ Greensboro, NC, USA \\ ${ }^{3}$ Jennings A. Jones College of Business, Department of Economics and Finance, \\ Middle Tennessee State University, Murfreesboro, TN, USA
}

Submitted August 2010. Accepted for publication June 2011.

\begin{abstract}
U.S. hospitals are under continual pressure both to increase productivity and to improve quality through the use of Health Information Technology. This paper analyzes 3,187 US hospitals, using data reported to the American Hospital Association, to assess changes in productivity over a fiveyear period (2002-2006). The Malmquist Indices derived indicate that Total Factor Productivity $(T F P)$ and Efficiency Change $(E F F C H)$ both increased during that timeframe. The low Technological Change (TC) index indicates that improvements to organizational processes did not contribute substantially to productivity. A secondary analysis examined the use of Computerized Physician Order Entry (CPOE) in relationship to the three indices. TFP trended positively for those hospitals further into the CPOE implementation process.
\end{abstract}

Keywords: hospital productivity, frontier analysis, quality improvement, computerized physician order entry (CPOE)

\section{INTRODUCTION}

The American Recovery and Reinvestment Act (ARRA) of 2009 offered an unprecedented set of financial incentives for providers to accelerate their adoption of certified electronic health records (EHR). The act outlines criteria, codified in December 2009, which defines "meaningful use" and links adoption to a pool of $\$ 19.2$ billion in incentives for hospitals and physicians. A key element of the U.S. healthcare reform targeted the effective use of information to support better decision-making and more effective care processes, resulting in improved health outcomes and reduced cost

\footnotetext{
* Corresponding Author: Timothy R Huerta, Rawls College of Business, Texas Tech University, MS 2101, Lubbock, TX 79409. Phone: (806) 742-1236. Fax: (806) 742-3434.

E-mail: tim.huerta@ttu.edu.

Other authors: ewford@uncg.edu; wfford@mtsu.edu; mark.thompson@ttu.edu.
} 
growth. To that end, the timetable for achieving EHR meaningful use had Computerized Provider Order Entry (CPOE) as the first capability target for 2011 in its matrix of care goals, data capture objectives and quality measures.

The ARRA includes incentives for early health information technology (HIT) adopters because evidence suggests that the widespread use of CPOE is fundamental to improving quality while safely reducing costs [1]. CPOE is an essential early step on the critical path to full adoption of the interoperable EHR technologies, because other applications, such as lab reports and decision support, rely on order entry as an initiating activity. Therefore, CPOE adoption is both an early goal and a cornerstone for those seeking to increase hospitals' productivity levels through technological change and more efficient operations. Despite the many positive reports about CPOE's efficacy [2], the positive relationship between $\mathrm{CPOE}$ and productivity gains is still a contested assertion [3].

The purpose of this paper is to evaluate the relationship between CPOE use and hospital productivity in the United States using longitudinal frontier analyses. In particular, hospitals' use of CPOE systems are compared to their Total Factor Productivity change specified using the Malmquist Indices. This study's plan of work involves four steps. First, the Malmquist Indices for measuring Technical Efficiency Change $(E F F C H)$, Technological Change $(T C)$ and Total Factor Productivity (TFP) over time are introduced and defined. Next, an empirical analysis of United States hospitals from 2002 through 2006 (5 years) is conducted to measure changes in efficiency, technological process change and total productivity. Third, the Malmquist Indices are analyzed in relationship to a measure of CPOE adoption status drawn from the Leapfrog Group's annual survey. The Leapfrog Group is a voluntary program aimed at leveraging employer purchasing power to recognize and reward safety, quality and customer value. The Leapfrog Hospital Survey provides data for comparing hospitals' performance on national standards of safety, quality and efficiency [4]. Finally, the implications of the study are discussed.

\subsection{New Contributions}

This research makes three important contributions to the health policy, administration and research literatures. First, the five-year period studied immediately follows the release of the Institute of Medicine [5, 6, 7] reports highlighting endemic process failures in U.S. hospitals and the emergence of large-scale efforts to address these failures $[8,9]$. Therefore, it empirically documents a period when significant effort to increase both EFFCH and TCs are likely to have occurred in the hospital sector. Additionally, the study provides a benchmark to measure the effectiveness of the ARRA pay-for-performance program.

Second, empirically demonstrating the link between increased productivity and CPOE adoption is an important aspect of promoting behavioral change. Further, the analysis performed herein can be replicated within health systems to compare discrete units' productivity levels and relate them to technology utilization. Therefore, frontier analyses offers an alternative approach that front-line managers might use to assess the effectiveness of their HIT implementations. 
Third, the method that yields the Malmquist Indices, Data Envelopment Analysis (DEA), is an important addition to the growing body of frontier analysis techniques being used by policy and health services researchers. At the facility level, measuring changes in hospitals' TFP and its related elements (viz., EFFCH and TC) can identify hospitals where best-demonstrated practices are likely to be the norm. At the market and national levels, the impact of meaningful use reforms designed to increase efficiency and improve processes can be assessed. For example, the economic stimulus legislation enacted in 2009 included over $\$ 19$ billion to promote HIT adoption in the near term [10]. Through 2019, that amount may rise to $\$ 38$ billion [11]. Given that major public and private investments designed to increase the hospital sector's productivity has been focused at the acute setting, research on the impact of CPOE diffusion will play a critical role as stories of success and failure begin to permeate the specialist and general practitioner community as they decide when and if to make the transition.

\subsection{Background on CPOE Diffusion}

The evolution of CPOE systems has proceeded gradually since the first one was introduced in 1969 [12]. However, as seen in many technology diffusion efforts, hightechnology products often require three, or even four, successive generations of product innovations and marketplace substitutions to achieve full diffusion [13]. Even when systems are adequately well developed, implementation can take extended periods of time [14] depending upon factors idiosyncratic to the organization [15]. For CPOE systems, there are still significant questions about the efficacy of the state-of-the-art. Given that the pace of product evolution likely impacts adoption and diffusion, innovation progress may accelerate adoption rates, but adoption may still proceed slowly, as predicted in other studies [16].

Several trends in the healthcare marketplace and literature support the likelihood of a longer time horizon. There have been several reports of costly CPOE system implementation failures [17]. Combined with the added costs and expected resistance to system introduction, these well-known barriers may cause administrators to take a wait-and-see approach to adoption. Further, in many settings, a fully usable CPOE system depends on the existence and interoperability of other technologies and systems [18]. As a result, the need for an operational electronic medical record (EMR) may be a rate-limiting first step in the implementation of a CPOE system throughout the organization. In addition, the ability to integrate CPOE systems into other existing information technologies, such as legacy billing systems, can slow adoption. Finally, and potentially more problematic for CPOE proponents, is the emergence of empirical studies questioning CPOE's clinical efficacy [19-21]. Given that these trends directly impact the two major adoption stakeholders - hospital administrators and clinicians, the barriers to CPOE adoption may be greater than previously estimated [22].

On the other hand, some trends seem to support an increase in the speed of CPOE adoption. First, the current generation of physicians is slowly being replaced with a generation of professionals with an increased familiarity with all forms of IT. This generational shift is resulting in a concomitant change in their expectations for clinical systems in the hospital environment, creating new internal influences on technology 
innovation [23]. As a result, it is likely that this new generation of physician users will bring with them a new cultural expectation for the use of CPOE systems. A second trend is the increased demand for electronically compiled clinical information in support of payment claims documentation. It is becoming increasingly impractical to have post hoc entry of orders and other diagnostic information, as more detail is required. Medicare, in particular, has both the leverage and expressed intent to support programs such as the Premier pay-for-performance demonstration [24, 25]. In technology diffusion terms, such changes to payment schemes represent important new external influences that may affect technology innovation and adoption rates. Thus, combined, CPOE technology, the population of end-users, and health care environment were all coevolving in ways that would accelerate diffusion in the future - even before the ARRA.

\subsection{Measuring Hospital Efficiency, Technological Change and Productivity}

While there are many and competing definitions of efficiency in the literature, they are all built on the same basic principle: the "transformation" of inputs to outputs. The Agency for Healthcare Research and Quality (AHRQ) uses a definition of efficiency that aligns with this perspective - "efficiency [is] as an attribute of performance that is measured by examining the relationship between a specific product of the health care system (also called an output) and the resources used to create that product (also called inputs)" [26].

Current efficiency measures can be classified in one of three basic forms: ratios, frontier analytic indices, and regression-based estimates. These forms can be simple or complex. Simple measures are those that focus on outputs and present themselves in the context of an input. This may be done in the form of either output alone, as in the case of patient discharges, or as a ratio of inputs to outputs such as Full Time Equivalent (FTE) personnel per discharge. Simple measures are advantageous because they are easy to understand and are relatively simple to implement as key performance indicators. However, simple measures often fail to provide actionable information because, while they explain "what", they do not explain "why" hospitals differ in their performance, and therefore point the way to performance improvements. Complex measures focus on the transformation rate $-\mathrm{T}$ in eqn. 1 - rather than the outputs. Complex measures are indicators of transformation, the rate at which inputs (I) are converted to outputs $(\mathrm{O})$, rather than the outputs themselves.

$$
I \stackrel{T}{\longrightarrow} O
$$

The most common analytic method in the literature for estimating the conversion rate of inputs to outputs is regression analysis; however, frontier analysis is gaining increased traction in healthcare. Frontier analysis offers a significant benefit over both simple models and competing complex models. Frontier analysis allows for multiple output variables to be used in the calculation along with multiple input variablesallowing a more holistic perspective on efficiency than that provided by simple output or ratios alone. The advantages of frontier analysis over regression are described below. 


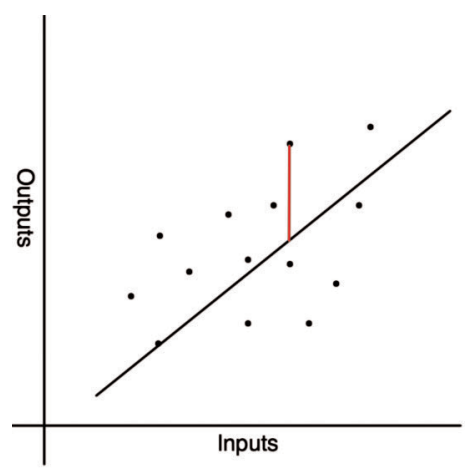

A Regression Appoach

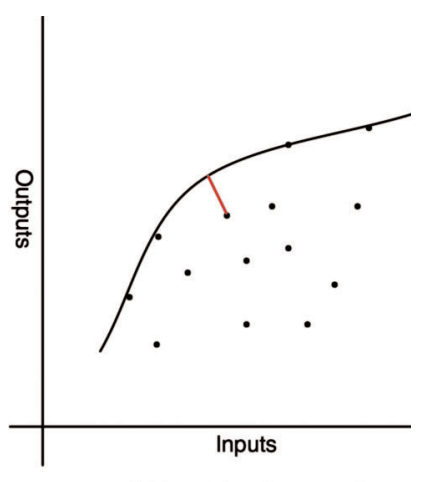

A Frontier Appoach

Figure 1. Comparing regression and frontier approaches

\section{METHODS}

\subsection{Methods of Analyzing Hospital Efficiency: Regression vs. Frontier Analysis}

Figure 1 provides an illustration of the basic dynamics of both regression and frontier approaches. In both cases, the data points are positioned identical and the axes in the figure support the argument advanced in eqn. 1 - inputs are used to create outputs. The purpose of regression is to identify the function that represents the average (mean) efficiency relationship between inputs and outputs. In that case, the line of best fit (the regression line) is the one that minimizes the squares of the deviations, and the slope of the regression line represents the average efficiency among the variables.

Frontier analysis takes a fundamentally different approach by looking for the best demonstrated practice: identifying the best demonstrated output for varying occasions of input. Frontier analysis gets its name because it seeks to identify the 'frontier' or 'leading edge' on which the most productive/efficient organizations balance input and outputs. In frontier analysis, the "residuals" then represent the distance of each observation from the best demonstrated practice frontier. These residuals represent the degree to which an observation falls short of expected production. Put another way, regression analysis identifies the line that best represents the relationship among variables, whereas frontier analysis identifies the line that represents the best relationship among variables.

The focus on best demonstrated practice aligns well with the move towards evidence based management through quality improvement iteration. While the regression model works on identifying the poor performers relative to the average standard, the frontier model focuses on identifying how far an individual observation is from its potential defined against the standard of best demonstrated practice.

\subsection{Longitudinal Efficiency: The Malmquist Indices}

Productivity analysis - a longitudinal approach to efficiency - is also linked to frontier analysis. The most commonly used productivity measurement devices used in the economics literature are the Fisher and Törnquist indices [27]. However, both of these 
measures require price data to assess productivity and that data is often either confidential or not clearly understood at the hospital level in healthcare. A third approach was developed by Malmquist in 1953 and was subsequently linked to frontier analysis, specifically DEA, by Caves, Christensen and Diewert [28] as an alternative to the Törnqvist [29] index. The Malmquist Total Factor Productivity (TFP) Index was further explored by Fare et al. [30] who proposed the use of linear programming to identity the frontier, facilitating analysis. In the end, research has found that, under the right conditions, the Malmquist, the Fisher and the Törnqvist indexes can be derived from one another [31].

TFP is an economic term to describe the transformation of inputs to outputs over time in a manner that accounts for all factors - both endogenous and exogenous. Rather than separating the two, TFP indexes simply describe the transformation over time. TFP is often seen as the real driver of growth. Some comparisons of national economies indicate that TFP may account for up to 60 percent of growth over time [32]. Therefore, understanding TFP, its parts and its impact is an important aspect of changing the way hospitals do business. The Malmquist TFP Index focuses on changes in productivity over time, and differs from the cross-sectional approach generally used in most frontier assessments like DEA and Stochastic Frontier Analysis (SFA) [33].

Healthcare is an ideal candidate for indexing using the Malmquist TFP Index. The Malmquist TFP Index is particularly useful when two conditions are satisfied: first, when the objectives of the firms are not known, have not been achieved, or differ from firm to firm; and, second, when output pricing information is either not available or is unusable because some outputs' values are purposely overstated. To the first issue, in the healthcare sector, the mix of for-profit, nonprofit (often religiously affiliated) and community ownership arrangements lead to differing strategies and goals for the organizations. To the latter issue, given that contracting arrangements with insurance companies and Medicare fee structures routinely mask true reimbursement rates relative to the largely fictional 'charges' the consumer usually experiences, the Malmquist indices can offer a useful productivity measure. Further, the reimbursement structure of US healthcare with specialists providing and billing for professional services creates distortions for understanding the true costs of providing those services. Uri [34] argued that the Malmquist approach was clearly superior for market or industry level assessment under such conditions.

Secondarily, and of significant impact in this research, the Malmquist TFP Index has a number of additional benefits for use in research in healthcare. First, while frontier analyses are non-parametric, the Malmquist is, in this case both parametric and normally distributed - a point not often raised in the literature. This emerges from the fact that the index is not limited to a number from zero to one, but rather takes a positive number centered on the overall shift in productivity. Further, the function is constructed so that degradation in performance manifests itself as an index of less than one, whereas an improvement in performance is presented by a Malmquist index greater than one. Second, the Malmquist TFP Index can be decomposed into two components: efficiency change $(\mathrm{EFFCH})$ and technological change (TC). Equation 2 illustrates the relationship between TFP, EFFCH and TC:

$$
T F P=\sqrt{E F F C H \times T C}
$$


The decomposition of TFP productivity has been widely explored in the literature, and more specifically, it has been used to explore issues in healthcare [35].

The EFFCH (i.e., X-inefficiency) component, on one hand, is an indicator of the 'management effect' on organizational performance. EFFCH is typically attributed to insufficient competitive pressures that allow management to perform at subpar productivity levels. Under competitive pressure, managers are incented to improve their underlying organizational processes in order to keep pace with other firms in the market through innovation. It occurs when more of each input is used than should be required to produce a given level of output in specific organizational activities [36].

On the other hand, the TC index measures shifts in the TFP frontier that arise from such organizational innovation. It is interpreted as the change of the "best practice" frontier over time typically due to improvements in the "technology" of organizational processes [37]. The term "technology" has a general meaning here and it refers not only to information or clinical technology innovations but to process innovations as well. The most significant technological changes in an organization often rely on behavior modifications rather than the implementation of technological systems. For instance, the reduction of hospital-acquired pressure ulcers at Ascension Health emerged from a redesign of the socio-technical system within the facility [38], resulting in a shift in demonstrated best practice. TC then is an important component of TFP because it identifies changes in the production frontier over time.

\subsection{CPOE's Projected Impacts on Workflows and Productivity}

When effectively implemented in hospitals, CPOE systems can enhance care quality, improve revenue cycle management systems and increase productivity [39]. Enhanced quality arises from factors including the use of clinical decision support to ensure that practice guidelines are met, reduced medical error rates [40], and more timely delivery of both test results and medications [41]. Improvements in revenue cycle management occur because paper records no longer need to be abstracted for billing purposes [42] and costly duplication of orders are avoided [43]. CPOE contributes to increased productivity by realigning workflows to remove repeated keying of orders (also a potential error source), simplifying and ensuring orders that are transmittal to the appropriate receiver, and reducing the need for allied health professionals to seek clarification from the clinician generating the order [44].

However, it should be noted that CPOE has mixed results [45]. The worst-case scenario arises when the CPOE implementation fails completely and a hospital reverts to its previous modes of operation. Not only are the costs of the system increased, but organizational trust in future EHR endeavors is undermined [46]. A more common concern is the shifts in costs associated with CPOE adoption. The most commonly cited negative impact arising from CPOE use is the additional time for physicians to electronically enter orders compared to handwritten or transcription modes of operation [47]. Historically, the value of physicians' time has been sufficiently greater than all other labor inputs. However, the economics of the healthcare workforce has changed dramatically. As a result, the net effect on hospital productivity of adopting CPOE technology is a complicated phenomenon to measure and analyze. 
A number of studies in the literature have used the Malmquist-based analysis to more deeply explore the root of productivity change. A Malmquist-based analysis not only provides an index that can be reconciled against the stage of adoption of CPOE to determine whether CPOE adoption is related to TFP, but also whether the efficiency gains emerge from shifts in management or shifts in tools - or put another way - how we do things versus what we do things with. We therefore posit three hypotheses.

H1: TFP will be systematically related to CPOE adoption;

$\mathrm{H} 2$ : EFFCH will be systematically related to CPOE adoption;

$\mathrm{H} 3$ : TC will be systematically related to CPOE adoption.

Further, we expect that as CPOE adoption progresses, there will be a concomitant increase productivity.

H4: TFP will increase as stage of CPOE adoption progresses;

$\mathrm{H}$ 5: EFFCH will increase as stage of CPOE adoption progresses;

H6: TC will increase as stage of CPOE adoption progresses.

\subsection{Malmquist Model Specification}

Our analysis began by drawing on similar input/output DEA models defined in the literature [26, 48, 49]. In a review of frontier analysis studies conducted by McGlynn et al. [26], common outputs included measures of health services, such as discharges and inpatient days. Inputs generally center on how resources in the organization were allocated, including the amount of resources allocated to labor and measures of available capital, such as beds. In the case of our model, total facility expenditures, the number of beds for each hospital, and the Case Mix Index (CMI) were used as inputs for the Malmquist model, and the number of admissions and patient days were used as outputs. While these variables are common for the literature, they do diverge in a single, and significant way - the use of CMI as an input variable.

In fact, the use of CMI has often been associated with outputs rather than inputs. Rosko and his colleagues have used Case Mix adjusted discharges in a number of papers [50-52]. This is because CMI is directly related to gross revenues for those patient admissions reimbursed under the prospective payment system by the Centers for Medicare and Medicaid Services (CMS). However, CMI is a global figure representing an inventory of Diagnosis Related Groups (DRGs) for a particular provider during a particular time frame. As such, CMI can also be seen as a proxy for the acuity of the patient catchment area served by the hospital. The variables used in the model specification are more fully described elsewhere [53] and are summarized in Table 1.

The analysis generated the Malmquist TFP Index, and was further broken down into components of EFFCH and TC. The five-year average of the Malmquist index, its standard deviation, and value range were generated. These variables were then compared to the Leapfrog Group's measures of technological change - CPOE adoption status. 
Table 1. List of inputs and outputs used in the Malmquist index calculations

\begin{tabular}{l|l}
\hline Variable name & Description \\
\hline Total Facility Expenditures & $\begin{array}{l}\text { Input - Total facility expenses including labor and } \\
\text { materials, excluding bad debt. }\end{array}$ \\
\hline Beds & $\begin{array}{l}\text { Input - Total number of licensed beds including general } \\
\text { surgery, intensive care unit, skilled nursing and other } \\
\text { bed types. }\end{array}$ \\
\hline CMI & $\begin{array}{l}\text { Input - The CMS measure of the average diagnosis- } \\
\text { related group weight for a facility's Medicare patient } \\
\text { volume. Used as a proxy for the overall facility acuity of } \\
\text { patient illness. }\end{array}$ \\
\hline Adjusted patient days & $\begin{array}{l}\text { Output - Total facility patient days (inpatient and } \\
\text { outpatient) minus nursing home unit discharges. }\end{array}$ \\
\hline Adjusted patient admissions & $\begin{array}{l}\text { Output - Total facility discharges (inpatient and } \\
\text { outpatient) minus nursing home unit discharges. }\end{array}$ \\
\hline
\end{tabular}

\subsection{Secondary Analyses Specification}

For the second stage of the analyses, it was necessary for the hospital to have responded to the Leapfrog Group's annual survey. A comparison of the Leapfrog Group sample and the balance of the facilities assessed in stage one (i.e., the DEA) was made. The data are presented in the context of understanding response bias in the Leapfrog sample.

The CPOE scale has five response levels. The highest level of adoption is 'Fully Implemented' (level 5) which indicates that at least 75 percent of a hospital's medication orders are transmitted via a CPOE system. The next two highest levels of adoption, labeled 'Good Progress' (level 4) and 'Good Early Stage Effort' (level 3), indicate that a hospital is moving toward the 'Fully Implemented' standard within the next two (level 3) to three (level 2) years. The final two reporting levels are 'Willing to Report Publicly' (level 2) and 'Did Not Disclose Information' (level 1). Hospitals that fail to progress through the adoption levels from one year's survey to the next have their scores lowered as part of the evaluation algorithm.

The Malmquist TFP index was analyzed using a One-way Analysis of Variance (ANOVA). Post hoc multiple comparisons of means were also conducted to determine whether the path of significance, if any, is consistent in that higher levels of CPOE attainment were positively correlated with TFP, EFFCH and TC.

\subsection{Dataset and Sample Descriptions}

Three data sources were employed for the analyses. The first was the American Hospital Association's (AHA's) Annual Survey for fiscal years 2002 through 2006 [54]. The CMI was drawn from the Centers for Medicare and Medicaid Studies (CMS) Inpatient Prospective Patients System for the same period [55]. The Leapfrog Group's 2006 Annual Survey provided data on CPOE [56]. Medicare provider number was used as the key variable and cross-referenced to ensure matches across various datasets. 
In order to be included in the TFP analyses, it was necessary to limit this analysis to facilities with complete data for the entire panel span. Altogether, 3,178 hospitals had complete responses for the five years included in the study. Among the facilities analyzed in the first stage, 1,462 responded to the Leapfrog Group's survey. Within this population, a smaller subset $(\mathrm{N}=963)$ were assessed on their adoption of CPOE.

The datasets used in this study were merged, cleaned, and cross-validated using Microsoft Excel. The Malmquist TFP Index, EFFCH and TC were calculated using DEAP 2.1 [57]. In order to assess whether or not these indexes correlate with other measures related to CPOE, a second set of analyses was also conducted. In particular, ANOVA algorithms were executed using the indexes as dependent variables, and measures drawn from the Leapfrog Group's annual survey as factors. Second stage analyses were conducted using SPSS 17.0 for Mac. Factor analysis and visualization on the input and output data were conducted using STATA for Mac.

\section{RESULTS}

U.S. hospitals' diachronic performance was evaluated using the Malmquist productivity and efficiency indices described earlier. Table 2 summarizes the three indices' geometric means for the period from 2002-2006 - inclusive. Hospitals experienced an average annual increase of 5.3 percent in $E F F C H$ over the five-year period. However, declining efficiency attributed to $T C$ component of the productivity measure largely offset the gains in the EFFCH factor. Overall, the Malmquist analysis indicates that TFP increased approximately six-tenths of one percent each year $($ mean $=1.0058)$ in the 3,187 hospitals that provided complete response to the AHA where CMI data were available from CMS.

Table 2. Summary of Malmquist Indices derived from the AHA and CMS data for participating U.S. hospitals (2002-2006)

\begin{tabular}{c|l|l|l|l}
\hline Variable & Mean & Std. Dev. & Min & Max \\
\hline EFFCH & 1.053 & 0.086 & 0.523 & 1.836 \\
TC & 0.958 & 0.062 & 0.794 & 1.373 \\
TFP & 1.006 & 0.064 & 0.515 & 1.709 \\
\hline
\end{tabular}

$N=3187$. All indices are geometric means. The standard deviation, minimum and maximum values are for individual facilities.

To further explore the utility of the Malmquist Indices (MI) for studying hospitals, additional measures of change were drawn from another survey. Specifically, respondents to the Leapfrog Group's annual survey were compared to non-respondents (see Table 3). As part of the secondary analysis, t-tests were run to compare the Leapfrog respondents' scores on the MI factors. Leapfrog respondents differed significantly on $E F F C H$ and TC factors relative to the rest of the sample. 
Table 3. T-test for difference between Leapfrog Group survey respondents and non-respondents

\begin{tabular}{lccccccc}
\hline & $\begin{array}{c}\text { Leapfrog } \\
\text { respondent } \\
\text { (Yes = 1) }\end{array}$ & $\mathbf{N}$ & Mean & $\begin{array}{c}\text { Std. } \\
\text { deviation }\end{array}$ & $\begin{array}{c}\text { Std. } \\
\text { error } \\
\text { mean }\end{array}$ & t-test & $\begin{array}{c}\text { Sig. } \\
\text { (2-sided) }\end{array}$ \\
\hline \multirow{2}{*}{$\mathrm{EFFCH}$} & 0 & 1462 & 1.0659 & 0.0934 & .0024 & 7.992 & $<.001$ \\
\hline \multirow{2}{*}{$\mathrm{TC}$} & 1 & 1725 & 1.0425 & 0.0728 & .0018 & & \\
\hline \multirow{2}{*}{$\mathrm{TFP}$} & 0 & 1462 & 0.9445 & 0.0649 & .0017 & -11.75 & $<.001$ \\
& 1 & 1725 & 0.9700 & 0.0572 & .0014 & & \\
& 0 & 1462 & 1.0031 & 0.0713 & .0019 & -2.231 & .026 \\
\hline
\end{tabular}

Table 4. ANOVA for Malmquist Indices and the use of CPOE by hospitals ${ }^{1}$

\begin{tabular}{ccccccc}
\hline Variable & & Sum of squares & df & Mean square & F & Sig. \\
\hline \multirow{4}{*}{ EFFCH } & Between Groups & 0.149 & 3 & & & \\
& Within Groups & 5.021 & 959 & .050 & 9.49 & $<0.001$ \\
& Total & 5.170 & 962 & .005 & & \\
\hline \multirow{2}{*}{ TC } & Between Groups & 0.207 & 3 & .069 & & \\
& Within Groups & 2.298 & 959 & .002 & 28.74 & $<0.001$ \\
& Total & 2.505 & 962 & & & \\
\hline \multirow{2}{*}{ TFP } & Between Groups & 0.010 & 3 & .003 & \multirow{2}{*}{1.04} & 0.373 \\
& Within Groups & 3.163 & 959 & .003 & & \\
\hline
\end{tabular}

${ }^{1}$ The ANOVA only includes the Leapfrog Group survey respondents.

The primary purpose of analyzing the Leapfrog respondents was to compare their MI scores to other performance standards. In particular, the CPOE measure from the Leapfrog survey was analyzed. Table 4 displays the comparison of MIs to the hospitals' $C P O E$ scores. Again, $E F F C H$ and TC measures had significant relationships to $C P O E$.

Post hoc analyses of the ANOVA measures were also performed to identify where significant differences exist in the Leapfrog survey variables' response levels vis-à-vis MI. The TFP measures' mean differences progressed in a positive linear fashion moving up the $C P O E$ scale. Therefore, the inference is that higher attainment levels on the CPOE scale are positively correlated with increased levels of TFP.

A factor analysis was performed on the input and output data to facilitate the visualization of the data. For both the inputs (eigenvalue $=1.76$ ) and outputs (eigenvalue $=2.19$ ), one factor was identified. Figure 2 illustrates a scatterplot representation of the data and the differences between the Leapfrog respondents and those that did not participate in the Leapfrog effort. The Leapfrog group tended to be higher volume facilities and, as a result, defined a distinct yet unique frontier. 




Figure 2. Scatterplot of factor scores for inputs and outputs with both regression and frontiers illustrated

\section{DISCUSSION}

Efforts to increase U.S. hospitals' productivity are meeting with mixed results. On the one hand, over the five years studied, managers were able to increase the output-toinput ratio and increase EFFCH levels in the sector. On the other hand, efforts to improve the underlying care processes (i.e., $T C$ ) are not succeeding to the extent that they made a positive contribution to TFP. Therefore, there has been a trade-off between the EFFCH and TC factors, resulting in negligible gains in overall TFP.

In this study, quality improvement measured as the mean $T C$ did not exceed unity (TC $>1$ ) over the period studied for the entire sample. Fortunately, that is not the entire story and some support for the Value Proposition can be seen in the comparison between the Leapfrog respondents' results and the rest of the sample presented in Table 3. The Leapfrog respondents are significantly higher in both TC and TFP MIs vis-à-vis the other hospitals studied, while not experiencing any significant drop-off in the $E F F C H$ measure. Therefore, it is possible to make meaningful technological improvements to organizational processes without adversely impacting efficiency or productivity.

The CPOE measure is significantly related to both the EFFCH and TC MIs that contribute to TFP; however, their impact seems to be a wash. The results from the present analyses indicate that hospital employees are working harder (i.e., increasing efficiency gains), but not necessarily smarter (i.e., effectively employing new 
technologies) in order to hold productivity constant. The $E F F C H$ measure does account for the majority of gains in overall productivity rather than $T C$. These results would seem to support the supposition that there is a trade-off between EFFCH and TC, related to $C P O E$. However, it should also be noted that there is a net positive, although there may be some positive impact on productivity on balance.

Computerization of clinical information is an essential component of a broader system of hospital changes. To gain productivity advantages from computers in healthcare settings, rather than simply computerizing the traditional practices, managers have to re-engineer the hospital to match workflows with the capabilities of computers. Therefore, it is necessary to implement work process changes throughout the hospital, which represents a major $T C$.

In addition, $C P O E$ is a networked technology. Networked technologies' efficiency increases as more users join the system. Therefore, the benefits of information technologies, such as $C P O E$, are not fully realized until their adoption reaches critical mass [58]. The time delay in the development of such symbiotic network connections is one reason economists give for the appearance of a Productivity Paradox, mainly because the return on investment (ROI) expected is beyond the typical payback horizon.

Nevertheless, there is more to implementing a CPOE system than mere technology. Computers need to be accompanied by a rethinking of job processes and employees' roles and responsibilities (i.e., scope of practice) as well as organizational hierarchy [59]. Among other things, this implies upgrading the skills of the workforce, which would impact $E F F C H$ favorably. For increasing productivity and fostering innovation, a multi-disciplinary educated workforce is critical. Nonetheless, many organizations retain their old structures because the required changes are time consuming, risky, and initially costly. In large part, this problem emerges because such changes are perceived as impinging on the professional domains of many clinically trained stakeholders physicians in particular [60]. Therefore, rather than changing the behavior or increasing the skills of current staffers, it is a more common strategy to add a costly specialist (i.e., outsourcing) to handle specific types of issues in professional domains. The increased use of scribes is one indication that this phenomenon may be occurring [61].

\subsection{Limitations and Future Research}

The study presented here suffers from several limitations. First, neither the AHA, CMS, nor Leapfrog Group surveys has complete information on all U.S. facilities for the entire period studied. CMS is limited to hospitals above a minimum size and further limited to only those that accept Medicare patients. The AHA and Leapfrog Group surveys are both voluntary. The favorable response bias that exists between the Leapfrog Group sub-sample and the rest of the facilities studied probably extends to those hospitals omitted from the analyses [62]. Therefore, the productivity gains for the period studied are not representative of the entire hospital sector. Further, the findings from these analyses are probably an overestimate of the entire sector's productivity performance.

Additionally, it would be useful to generate information on allocative efficiency using the Fisher [63] and Törnqvist [29] productivity indices. However, such models 
require better service pricing information that is not widely available. Indices that include accurate pricing data would be more directly applicable to the study of policy changes designed to increase productivity by using global payment schemes. Such policies are central to many healthcare reform plans being promoted at the outset of the Obama administration [64].

One possible solution to both the reliability issue associated with voluntary surveys would be to rely exclusively on CMS data to conduct hospital productivity analyses. The fidelity of the facilities' submissions would be better assured because false reporting would constitute fraud and be punishable. Because CMS has the payment information related to its Medicare enrollees, other productivity analyses could be conducted. In addition, CMS has a complete census of hospitals. This would reduce many of the statistical concerns that researchers have raised related to using DEA [65]. Lastly, the larger data set would increase the sample size and potentially remedy the statistical power issue discussed above in the $C P O E$ analysis. The disadvantage to this approach, as stated earlier, is that CMS data underrepresent smaller, rural and critical access hospitals.

Another option for addressing the power issue is to use market-level analytic approaches. Both hospitals' technological processes and technical efficiency are linked to the markets they operate in. Previous studies have successfully used market-bymarket analytic strategies [e.g., 53, 66]. Further, identifying entire markets that have above average $T C$ and $E F F C H$ paradigms would make the search for best-demonstrated practices easier to translate into evidence-based practices.

However, the use of CMS data does not increase the availability of historic CPOE data. The largest dataset for that variable is the Leapfrog Group's data. In 2010, AHA began collecting data on CPOE. As those data become available over a longer time frame, the present study will provide the basis for exploring those data. Further, as attitudes change and programs to reward increased e-prescribing are expanded [67], there should be an impact on CPOE adoption. As a result, other factors that are not directly measured may be contributing to the productivity gains observed. Further direct examination of providers' attitudes is warranted.

\section{CONCLUSIONS}

For the sample of U.S. hospitals studied, total productivity levels (TFP) increased from 2002 to 2006, but only to a small degree. Further, the productivity gains are the result of increased $E F F C H$ rather than changes in the underlying technological processes (TC) used in facilities. Nevertheless, there are positive trends occurring in parts of the hospital sector.

Hospitals that are willing to make their progress in implementing evidence-based patient safety practices publicly available through the Leapfrog Group's Annual Survey are experiencing above average gains in both $T C$ and $T F P$. For managers, our secondary analyses indicate that implementing $C P O E$ is likely to have the greatest impact on productivity in the near term. For policymakers, our findings reinforce the fact that public reporting, or transparency [68], is a critical feature for making meaningful changes to the way hospitals execute their activities. 
These findings, coupled with a growing body of research [69] that hospitals engaged in public reporting deliver above average quality, are important for promoting and realizing the aims of the ARRA. Therefore, both policymakers and managers should promote the simultaneous pursuit of productivity gains, quality improvement, and increased reporting transparency in their initiatives. Merely pursuing payment reform policies, without linking them to discreet $T C \mathrm{~s}$, does not appear to be an effective strategy [70], and may delay the ROI for early adopters [71].

\section{CONFLICT OF INTEREST: None.}

\section{NOMENCLATURE}

$\begin{array}{ll}\text { AHA } & \text { American Hospital Association } \\ \text { CMI } & \text { Case Mix Index } \\ \text { CPOE } & \text { Computerized Provider Order Entry } \\ \text { CMS } & \text { Centers for Medicare and Medicaid Studies } \\ \text { DEA } & \text { Data Envelopment Analysis } \\ \text { I } & \text { Inputs } \\ \text { LF } & \text { Leapfrog Group } \\ \text { O } & \text { Outputs } \\ \text { EFFCH } & \text { Technical Efficiency Change } \\ \text { TC } & \text { Technology Change } \\ \text { TFP } & \text { Total Factor Productivity } \\ \text { T } & \text { Transformation Function }\end{array}$

\section{REFERENCES}

[1] Doolan, D.F. and D.W. Bates, Computerized physician order entry systems in hospitals: Mandates and incentives. Health Affairs, 2002. 21(4): p. 180.

[2] Taylor, R., J. Manzo, and M. Sinnett, Quantifying value for physician order-entry systems: A balance of cost and quality. Healthc Financ Manage, 2002. 56(7): p. 44-8.

[3] Sidorov, J., It ain't necessarily so: The Electronic Health Record and the unlikely prospect of reducing health care costs. Health Affairs, 2006. 25(4): p. 1079.

[4] Leapfrog Group Homepage. [Website] 2011 June 5, 2011]; Available from: http://www.leapfroggroup.org/.

[5] Kohn, L.T., J.M. Corrigan, and M.S. Donaldson, eds. To err is human: Building a safer health system. 1999, National Academy Press: Washington, D.C.

[6] Institute of Medicine, Crossing the quality chasm: A new health system for the 21st century2001, Washington, D.C.: National Academy Press.

[7] Aspden, P., et al., eds. Patient safety: Achieving a new standard for care. 2004, The National Academies Press: Washington, D.C.

[8] HealthGrades, Patient Safety in American Hospitals, 2004: Lakewood, CO. p. 1.

[9] Devers, K. and G.Y. Liu, Leapfrog patient-safety standards are a stretch for most hospitals, in Issue Brief No. 772004, Center for Studying Health System Change.

[10] Conde, C., Electronic medicine: Stimulus bill encourages HIT use. Tex Med, 2009. 105(5): p. 16-22.

[11] Cunningham, R., Stimulus bill implementation: expanding meaningful use of health IT. NHPF Issue Brief, 2009(834): p. 1-16.

[12] Goolsby, K. The story of evolving the world's first Computerized Physician Order Entry system and implications for today's CPOE decision makers. BPO Outsourcing Journal, 2002. 
[13] Norton, J.A. and F.M. Bass, A diffusion theory model of adoption and substitution for successive generations of high-technology products. Management Science, 1987. 33(9): p. 1069-1086.

[14] Sjoborg, B., et al., Design and implementation of a point-of-care computerized system for drug therapy in Stockholm metropolitan health region - Bridging the gap between knowledge and practice. International Journal of Medical Informatics, 2007. 76(7): p. 497-506.

[15] Snyder, R., et al., Computerized provider order entry system field research: The impact of contextual factors on study implementation. International Journal of Medical Informatics, 2006. 75(10-11): p. 730-740.

[16] Ford, E.W., et al., Computerized Physician Order Entry (CPOE) adoption in U.S. hospitals: Can the federal mandate be met? . International Journal of Medical Informatics, 2008. 77(2).

[17] Heeks, R., Health information systems: Failure, success and improvisation. International Journal of Medical Informatics, 2006. 75(2): p. 125-137.

[18] Lovis, C., et al., Comprehensive management of the access to the electronic patient record: Towards trans-institutional networks. International Journal of Medical Informatics, 2007. 76(5-6): p. 466-470.

[19] Kremsdorf, R., CPOE: Not the first step toward patient safety. Health Management Technology, 2005. 26(1): p. 66, 65 .

[20] Han, Y.Y., et al., Unexpected increased mortality after implementation of a commercially sold computerized physician order entry system. Pediatrics, 2005. 116(6): p. 1506-12.

[21] Mirco, A., et al., Medication errors in an internal medicine department. Evaluation of a computerized prescription system. Pharmacy World \& Science, 2005. 27(4): p. 351-2.

[22] Anderson, J.G., Social, ethical and legal barriers to E-health. International Journal of Medical Informatics, 2007. 76(5-6): p. 480-483.

[23] Ford, E.W., N. Menachemi, and M.T. Phillips, Predicting the adoption of electronic health records by physicians: When will health care be paperless? Journal of the American Medical Informatics Association, 2006. 13(1): p. 106-12.

[24] Becker, C., Time to pay for quality. CMS will partner with premier in trial project to give financial bonuses to hospitals that deliver the best care. Mod Healthc, 2003. 33(26): p. 6-7, 16, 1.

[25] Tieman, J., Experimenting with quality. CMS-Premier initiative to reward best, punish worst. Modern Healthcare, 2003. 33(28): p. 6.

[26] McGlynn, E.A., Identifying, Categorizing, and Evaluating Health Care Efficiency Measures. Final Report (prepared by the Southern California Evidence-based Practice Center-RAND Corporation, under Contract No. 282-00-0005-21). AHRQ Publication No. 08-0030, 2008, Agency for Healthcare Research and Quality: Rockville, MD.

[27] Reinsdorf, M.B., W.E. Diewert, and C. Ehemann, Additive decompositions for Fisher, Törnqvist and geometric mean indexes Journal of Economic and Social Measurement, 2002. 28(1): p. 51-61.

[28] Caves, D., L. Christensen, and W. Diewert, The economic theory of index numbers and the measurement of input, output, and productivity. Econometrica (pre-1986), 1982. 50: p. 1393-1414.

[29] Törnqvist, L., The Bank of Finland's Consumption Price Index. Bank Finland Monthly Bulletin, 1936. 10: p. $1-8$.

[30] Fare, R., S. Grosskopf, and P. Roos, The Malmquist Total Factor Productivity Index: Some remarks. SSRN eLibrary, 1995.

[31] Malmquist, S., et al., Index Numbers: essays in honor of Sten Malmquist1997, New York: SpringerVerlag.

[32] Easterly, W. and R. Levine, What have we learned from a decade of empirical research on growth? . The World Bank Economic Review, 2001. 15(2): p. 177-219.

[33] Giuffrida, A., Productivity and efficiency changes in primary care: A Malmquist index approach. Health Care Management Science, 1999. 2(1): p. 11.

[34] Uri, N.D., Productivity change, technical progress, and efficiency improvement in telecommunications. Review of Industrial Organization, 2001. 18(3): p. 283-300. 
[35] Kontodimopoulos, N. and D. Niakas, A 12-year analysis of Malmquist total factor productivity in dialysis facilities. J Med Syst, 2006. 30(5): p. 333-42.

[36] Isik, I., Bank ownership and productivity developments: Evidence from Turkey. Studies in Economics and Finance, 2007. 24(2): p. 115.

[37] Salehirad, N. and T. Sowlati, Productivity and efficiency assessment of the wood industry: A review with a focus on Canada. Forest Products Journal, 2006. 56(11/12): p. 25.

[38] Pryor, D., et al., The Quality 'Journey' At Ascension Health: How We've Prevented At Least 1,500 Avoidable Deaths A Year-And Aim To Do Even Better. Health Affairs, 2011. 20(4): p. 604-611.

[39] Kaushal, R., et al., Return on investment for a computerized physician order entry system. Journal of the American Medical Informatics Association, 2006. 13(3): p. 261-6.

[40] Devine, E.B., et al., The impact of computerized provider order entry on medication errors in a multispecialty group practice. J Am Med Inform Assoc, 2010. 17(1): p. 78-84.

[41] Kuperman, G.J. and R.F. Gibson, Computer physician order entry: Benefits, costs, and issues. Annals of Internal Medicine, 2003. 139(1): p. 31-9.

[42] Weiss, A.M. and A. Jain, Using computerized physician order entry to decrease insurance denials. AMIA Annu Symp Proc, 2005: p. 1152.

[43] Jayawardena, S., et al., Prescription errors and the impact of computerized prescription order entry system in a community-based hospital. Am J Ther, 2007. 14(4): p. 336-40.

[44] Cheng, C.H., et al., The Effects of CPOE on ICU workflow: An observational study. AMIA Annu Symp Proc, 2003: p. 150-4.

[45] Stone, W.M., et al., Impact of a computerized physician order-entry system. J Am Coll Surg, 2009. 208(5): p. 960-7; discussion 967-9.

[46] Connolly, C., Cedars-Sinai doctors cling to pen and paper, in Washington-Post2005: Washington, D.C. p. A1.

[47] Devine, E.B., et al., Electronic prescribing at the point of care: A time, motion study in the primary care setting. Health Services Research, 2010. 45(1): p. 152-171.

[48] Carey, K., Hospital cost efficiency and system membership. Inquiry: The Journal of Health Care Organization Provision and Financing, 2003. 40(1): p. 25-38.

[49] Hussey, P.S., et al., A Systematic Review of Health Care Efficiency Measures. Health Services Research, 2009. 44(3): p. 784-805.

[50] Rosko, M.D., Cost efficiency of U.S. hospitals: A stochastic frontier approach. Health Econ, 2001. 10(6): p. 539-51.

[51] Rosko, M.D., Impact of HMO Penetration and Other Environmental Factors on Hospital XInefficiency. Medical Care Research \& Review, 2001. 58(4): p. 430.

[52] Rosko, M.D. and J. Proenca, Impact of Network and System Use on Hospital X-Inefficiency. Health Care Management Review, 2005. 30(1): p. 69-79.

[53] Huerta, T.R., et al., Testing the hospital value proposition: an empirical analysis of efficiency and quality. Health Care Management Review, 2008. 33(4): p. 341-349.

[54] American Hospital Association Annual Survey, 2009, Health Forum: Chicago.

[55] Center for Medicare and Medicaid Studies, Inpatient Prospective Payment System (IPPS) Public Use Files, 2009, Department of Health and Human Services.

[56] Leapfrog Group Hospital Survey, Leapfrog Group, Editor 2007: Washington DC.

[57] Coelli, T., et al., An introduction to efficiency and productivity analysis. 2nd ed2005, New York: Springer.

[58] Ford, E.W., et al., Prediciting Computerized Physician Order Entry (CPOE) adoption in U.S. hospitals: Can the federal mandate be met? International Journal of Medical Informatics, 2008. 77(2).

[59] Chapman, G. Innovation: The "productivity paradox" requires a human solution. 1997.

[60] Blake, S.C., et al., Facilitators and barriers to 10 National Quality Forum safe practices. Am J Med Qual, 2006. 21(5): p. 323-34. 
[61] Anonymous, Do your docs need scribes to use an EMR? MGMA Connex, 2008. 8(5): p. 13.

[62] Lin, I.F. and N.C. Schaeffer, Using survey participants to estimate the impact on nonparticipation. Public Opinion Quarterly, 1995. 59: p. 236-258.

[63] Fisher, I., The Making of Index Numbers1922, Boston: Houghton-Mifflin.

[64] Mechanic, R.E. and S.H. Altman, Payment reform options: Episode payment is a good place to start. Health Aff (Millwood), 2009.

[65] Newhouse, J.P., Frontier estimation: How useful a tool for health economics? Journal of Health Economics, 1994. 13: p. 317-322.

[66] Bates, L.J., K. Mukherjee, and R.E. Santerre, Market structure and technical efficiency in the hospital services industry: A DEA approach. Med Care Res Rev, 2006. 63(4): p. 499-524.

[67] Steinbrook, R., The (slowly) vanishing prescription pad. N Engl J Med, 2008. 359(2): p. 115-7.

[68] Francis, T., How to size up your hospital; Improved public databases let people compare practices and outcomes, in Wall Street Journal2007. p. D.1.

[69] Jha, A.K., et al., Does the Leapfrog program help identify high-quality hospitals? Jt Comm J Qual Patient Saf, 2008. 34(6): p. 318-25.

[70] Kahn, C.N., Payment reform alone will not transform health care delivery. Health Aff (Millwood), 2009.

[71] Rogers, E., Diffusion of Innovations. (Fourth ed.) 1995, New York: The Free Press. 


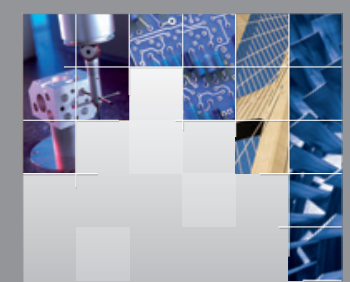

\section{Enfincering}
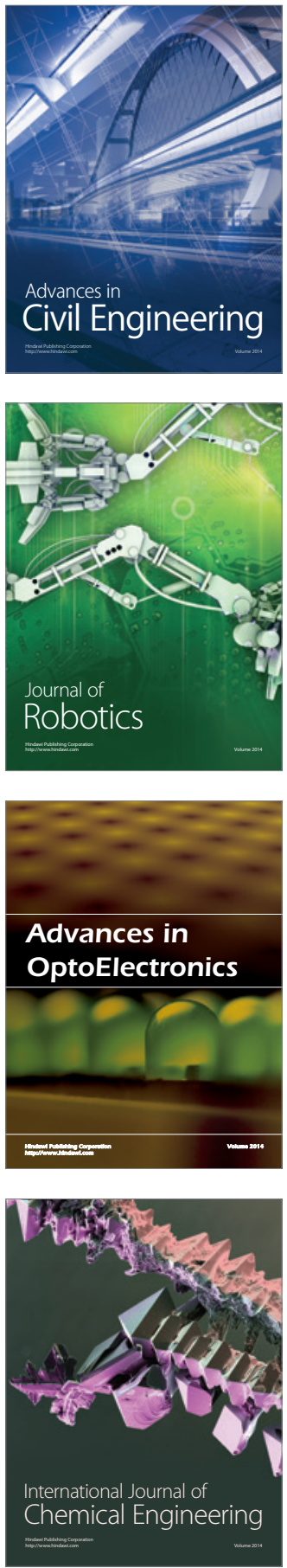



The Scientific World Journal

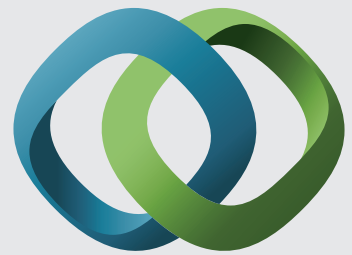

\section{Hindawi}

Submit your manuscripts at

http://www.hindawi.com
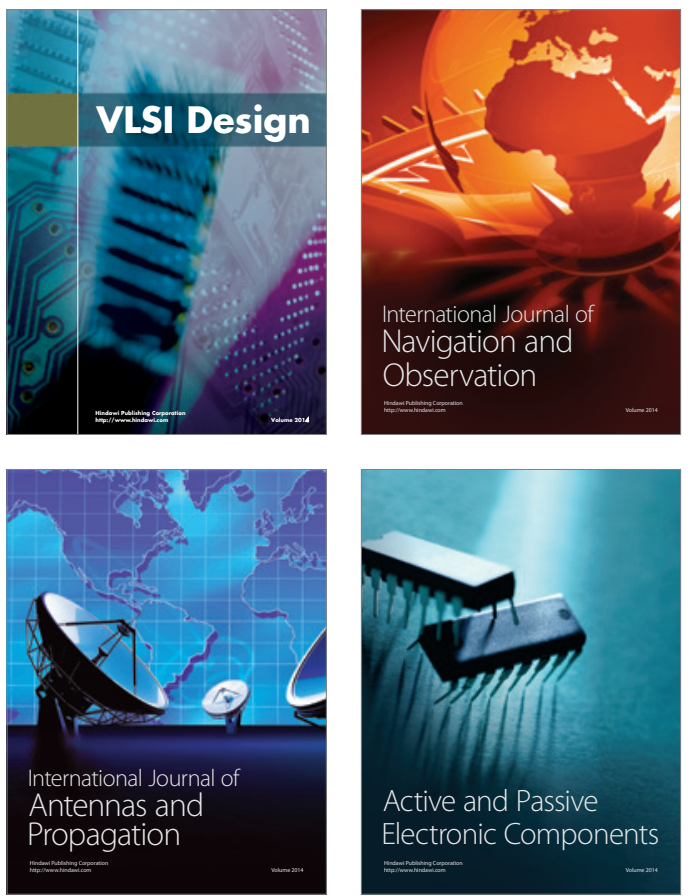
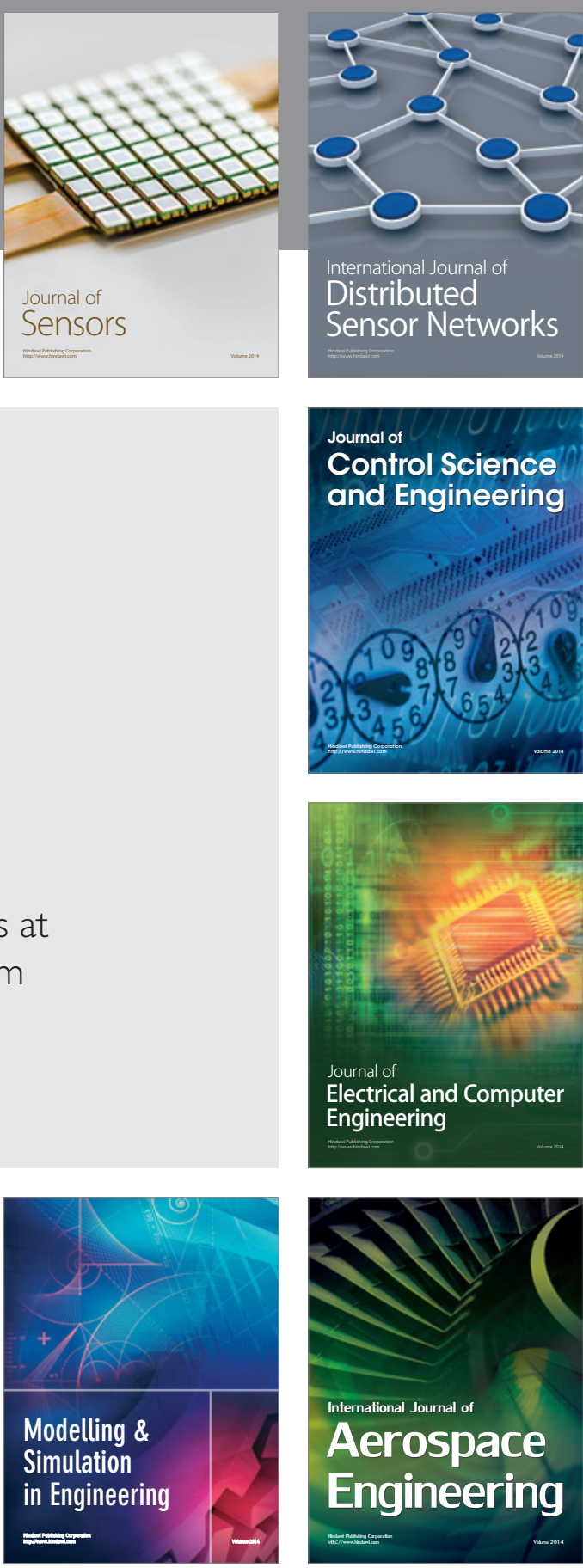

International Journal of

Distributed

Sensor Networks

Journal of

Control Science

and Engineering
